\title{
Required displacement factors for evaluating and comparing climate impacts of intensive and extensive forestry in Germany
}

Christian Buschbeck ( $\nabla$ christian.buschbeck@indecol.uni-freiburg.de )

University of Freiburg

\section{Stefan Pauliuk}

University of Freiburg

\section{Methodology}

Keywords: Forest Management, Wood utilization, Carbon Storage, Carbon Balance, Displacement Factor, Substitution, Decarbonizati

Posted Date: February 9th, 2022

DOI: https://doi.org/10.21203/rs.3.rs-1317454/v1

License: (c) (i) This work is licensed under a Creative Commons Attribution 4.0 International License.

Read Full License 


\title{
Required displacement factors for evaluating and comparing climate impacts of intensive and extensive forestry in Germany
}

\author{
Buschbeck, Christian* \\ Industrial Ecology Group, Faculty of Environment and Natural Resources \\ University of Freiburg; Tennenbacher Strasse 4 \\ christian. buschbeck@indecol. uni-freiburg. de \\ Pauliuk, Stefan \\ Industrial Ecology Group, Faculty of Environment and Natural Resources \\ University of Freiburg; Tennenbacher Strasse 4 \\ stefan.pauliuk@indecol.uni-freiburg. de \\ *Corresponding Author
}

February 4, 2022 


\section{Abstract}

\section{Background}

Forestry plays a major role in climate change mitigation. However, which intensity of logging is best suited for that task, remains controversial. We contribute to the debate by quantitatively analyzing two different forest management scenarios in Germany, an intensive and an extensive one. We assess whether increased carbon storage in wood products and substitution of other emission-intensive materials can offset reduced carbon stocks in the forest due to increased harvesting. For that, we calculate annual Required Displacement Factors (RDF) - a dimensionless quantity that indicates the minimal Displacement Factor (DF) so that intensive forestry outperforms extensive forestry from a climate perspective.

\section{Results}

Annual RDFs show values of about 1 in the first two decades and after 2030 a steady decline to about 0 . The comparison between current average DF and calculated RDFs indicates that for now, a compensation of lower carbon stocks in forests by material and energy substitution as well as product carbon storage is possible. In the future however, DFs will decline due to a decarbonization of the economy, hence the net climate mitigation potential of substitution diminishes. In terms of total global warming potential, the performance of the two scenarios is likewise dependent on how quickly the rest of the economy decarbonizes: With a conservative estimate on future emission reduction, leading to relatively high DFs, intensive forestry is beneficial, reducing total global warming potential (GWP) over the analysed time period of 40 years by $100-300 \mathrm{Mt}$ $\mathrm{CO} 2$-equ. compared to extensive forestry. With an optimistic estimate for low future DFs extensive forestry is beneficial, reducing GWP over the same time period by 0 - $200 \mathrm{Mt} \mathrm{CO2-equ.} \mathrm{compared} \mathrm{to} \mathrm{intensive} \mathrm{forestry.}$

\section{Conclusion}

Our findings highlight the necessity of a broad systems perspective for assessing the climate impacts of wood use. Robust statements about the climate performance of different forestry scenarios can only be made by including different possible industry decarbonisation pathways into the assessment. Still, we can robustly conclude that the later a change in forest management is initiated, the more beneficial the extensive scenario will be, because carbon displacement diminishes as decarbonization proceeds. 


\section{Keywords}

Forest Management, Wood utilization, Carbon Storage, Carbon Balance, Displacement Factor, Substitution, Decarbonization 


\section{Acronyms}

DCF cynamic characterization Factors. 9

DF displacement factor. 5

DLCA dynamic life cycle assessment. 7

EF extensive forestry. 10

GHG greenhouse gas. 6

GWP global Waming potential. 6, 9

HWP harvested Wood product. 5

IF intensive forestry. 10

IPCC intergovernmental panel on climate change. 6

LCA life cycle assessment. 9

LULUCF land use, land use change and forestry. 5

NPS nature conservation preference scenario. 14

RDF required displacement factor. 6

WPS wood preference scenario. 14 


\section{Introduction}

The question of how German forests should be managed in the future is highly topical (BMEL 2021). In addition to the fulfillment of different ecosystem services, the climate impact of forest management is of central importance, since their potential to act as carbon sink represents an effective tool for mitigating climate change. Accordingly, the German government has set its focus on the sink capacity of German forests in order to achieve carbon neutrality in the coming decades. For the carbon footprint of the land use, land use change and forestry (LULUCF) sector, ambitious targets have been set for future decades (-25 mio t $\mathrm{CO}_{2}$-equ. in 2030, -35 mio t $\mathrm{CO}_{2}$-equ. in 2040 (J. Bauhus et al. 2021) ). However, according to a projection by the Federal Environment Agency, it is not possible to meet these targets by continuing current management practices (Emele, Harthan, R.,O., and Moosmann 2019). New calculations based on more recent data come to the same conclusion, although the emission gap is less severe (3 to $17 \mathrm{Mt} \mathrm{CO} 2$-eq. instead of 45) (Hennenberg et al. 2021). In order to meet the carbon sequestration goals of the German government, it would be necessary to reduce logging, which in turn would cause higher greenhouse gas emissions in other sectors (e.g. the construction sector) or export countries (J. Bauhus et al. 2021). The assessment of climate benefits of forest management thus not only depends on actions and measures in the forest sector but also on carbon intensity of energy supply and material production. Such cross-sectoral relationships highlight the necessity of consequential approaches ("how are the global environmental burdens affected by the production and use of the product ?" Ekvall (2019)) in addition to the attributive approach ("what share of the global environmental burdens belongs to a product?" Ekvall (2019)), for assessing climate impacts of forest systems (Brander, Burritt, and Christ 2019). Many studies apply consequential approaches to assess whether intensive or extensive forest management is more beneficial for mitigating climate change, though the results are controversial. The main two reasons in favor of intensive forestry is that an increase in wood utilization can offset decreased carbon stocks in the forest by storing more carbon in harvested Wood product (HWP) and by substituting more $\mathrm{CO}_{2}$-intensive materials and services. (Leif Gustavsson et al. 2017; L. Gustavsson et al. 2021; Xu et al. 2018). Proponents of extensive forestry state the opposite (Leturcq 2020; Seppälä et al. 2019; Kalliokoski et al. 2020; Soimakallio et al. 2021). This dissent can have several causes. For example, with regard to German forests, the controversy is related to the robustness of the carbon sequestration scenarios produced by different forest growth models used (Böttcher et al. 2018; Jürgen Bauhus et al. 2018). The chosen time horizon can also have an impact: In L. Gustavsson et al. (2021) a very long time period of 200 years is analyzed. Climate impacts during the first decades of the modeling period promote extensive forestry and benefits of intensive forestry are only visible in the long run. Other studies, that focus on shorter time horizons may ignore such long-term effects in the carbon balance (Soimakallio et al. 2021).

Another dominant factor for divergent results in climate impact assessment is the choice and application of displacement factor (DF) (Baul et al. 2020). They 
indicate how much carbon emissions would be avoided (substituted) by using wood instead of a non-wood alternative, and are defined as follows.

$$
D F=\frac{G H G_{n o n-w o o d}-G H G_{W o o d}}{W U_{W o o d}-W U_{n o n-w o o d}}
$$

"Where $G H G_{n}$ on - wood and $G H G_{w}$ ood are the GHG emissions resulting from the use of the non-wood and the wood alternatives, respectively, expressed in mass units of carbon (C) corresponding to the $\mathrm{CO}_{2}$ equivalent of the emissions, and WUwood and WUnon-wood are the amounts of wood used in the wood and non-wood alternatives, respectively, expressed in mass units of $\mathrm{C}$ contained in the wood" (Sathre and O'Connor 2010). A vast variety of DF estimates exist in the literature but there is a lack of coherence, transparency and robustness in thos estimates (Tanja Myllyviita et al. 2021). Therefore we refrain from calculating climate impacts with fixed DFs in this study. Instead, DFs are treated as uncertain and scenario dependent variable. A method with a similar approach called required displacement factor (RDF), was already introduced by Seppälä et al. (2019). It can be used to compare climate impact assessments of different forest management scenarios, and is not subject to the

same uncertainties as DFs, because RDFs are solely calculated on the basis of forest dynamics.

\subsection{Required Displacement Factors for comparing the cli- mate benefit of two forest management scenarios}

RDFs are defined as the minimum DF that would be required for intensive forestry to climate wise outperform extensive (Seppälä et al. 2019). They are used to compare different forest management scenarios and are based on the assumption, that more raw wood can be used in an intensive forestry scenario compared to an extensive forestry scenario, resulting in larger substitution effects in the former. The only necessary input to calculate RDFs are parameters from forest growth modeling because DFs are treated as exogenous parameter. Additionally, by comparing calculated RDFs and DFs, a statement can be made about the climate impact of the different scenarios: If the average DF of wood use is higher than the RDF, the GWP of the intensive scenario is lower than that of the extensive (and vice versa). In doing so however, uncertainty of DFs would need to be addressed and discussed properly

In a typical scenario comparison the global Waming potential (GWP) of both scenarios is calculated based on forest carbon stocks, HWP carbon stocks and substituted greenhouse gas (GHG) emissions. Forest carbon stocks can be derived from forest growth modelling and displaced emissions are calculated by multiplying DFs with the difference in wood used for a specific material substitution. For calculating HWP carbon stocks different methods have been elaborated during the last decades. In 2006 the intergovernmental panel on climate change (IPCC) proposed three different approaches (Pingoud et al. 2006) from which the production approach was recommended for good practice a few years later (Hiraishi et al. 2014). In this approach, only wood products from 
domestically harvested wood is inventoried, leaving out changes in the wood product pool due to international trade (Yang and Zhang 2016). Despite these shortcomings it has been the most commonly used approach to assess HWP carbon stock in the last decade. Evidently, estimating HWP stocks is challenging and induces uncertainties, because the import and export of wood, as well as inherited emissions from the HWP stock before the modeling period, have to be dealt with (Pukkala 2014; Zhang et al. 2020; Yang and Zhang 2016). In contrast to a country specific carbon balance, where HWP carbon stocks are needed to correctly allocate climate impacts, the calculation of RDFs does not require them. Here, uncertainties could be evaded by deploying an alternative approach to assess climate impacts of carbon storage in products, which does not rely on HWP stocks.

So far, no RDFs have been computed for German forest management scenarios. RDF estimates exist for Finnish forests, with Seppälä et al. (2019) calling for application of their method to other countries. We add to this method a different approach for assessing the effect of temporal carbon storage in wood products and study how increasing the lifetime of wood products (through more sustainable wood use, such as cascade use (Höglmeier et al. 2015)) affects RDF.

\subsection{Goal and Scope definition}

In this work, we calculate RDFs for the management of German forests, evaluating published scenarios from forest growth models. This consequential approach complements the attributive, sectoral approach for which GWP assessments are available. In calculating RDFs, we propose a new method that deploys dynamic life cycle assessment (DLCA) (Levasseur et al. 2010) to quantify the temporary storage of carbon within HWPs instead of the usual methodology which uses HWP carbon stocks. RDFs are calculated for several different average wood product storage times to shed light on this important technical parameter. Fi-

nally, the calculated RDFs are related to current average, and future estimated DFs for different national climate policy scenarios. This will test the assumption as to whether, from a climate perspective, higher storage and substitution effects can outweigh reductions in forest carbon stocks. 


\section{Methods}

\subsection{System definition}

The forest - wood system is divided into two subsystems (Figure 1). In the forest system, carbon enters via sequestration $(C S)$, and leaves the forest in form of emissions $(C E F)$ (transpiration, decomposition of biomass, etc.) as well as in carbon stored in harvested wood $(C W 2)$. The sum of these three fluxes gives the carbon stock changes of the forest $\triangle C F$, via the mass balance at each. All three take place at the same point in time $(\mathrm{t}=\mathrm{y})$. After harvest the carbon sequestered in the wood enters the HWP system. Due to wood utilization, GHG emission outside the system boundary are displaced. At the end of the HWP lifetime the carbon stored in it is released as emission $(C E P)$. Thus, the HWP system is carbon neutral. The only difference in carbon uptake and release in the wood product system is its timing $(\mathrm{t}=\mathrm{y}$ and $\mathrm{t}=\mathrm{y}+\mathrm{z}$, respectively). Note here, that HWP does not only refer to material wood usage but also energetic usages. For this work, the carbon fluxes shown are considered on an annual basis, i.e., annual carbon stock changes and annual extraction of biogenic carbon are accounted for.

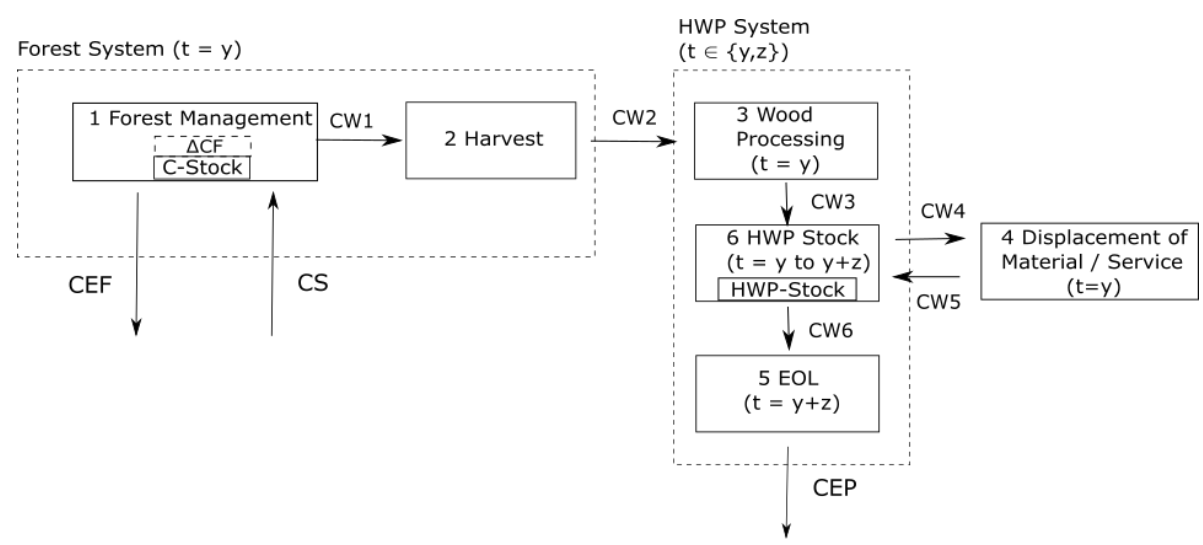

Figure 1: Shows the system definition for the system under study. Forest system and wood system are two different subsystems. The forest system is considered at time $y$ (= year of wood extraction), the product system at time $y$ and $y+z$ (= end of life of the wood product). CEF denotes the carbon emission of the forest and CS for the carbon sequestration. CW1 to CW4 denote the carbon contained in wood and CEP the carbon emissions at the end of life (EOL) of the HWP 


\subsection{RDFs with dynamic LCA}

In accordance with the system definition (Figure 1) the carbon balances for the two subsystems can be formulated. As convention for life cycle assessment (LCA), flows to the atmosphere have a positive sign, those from the atmosphere have negative sign. Accordingly, export of carbon from one product system to another has a positive, and import negative sign.

$$
-C S+C E F+C W 2-C W 2+C W 4-C W 5+C E P=\triangle C A T M
$$

Where $\triangle C A T M$ denotes for the carbon change in the atmosphere induced by the wood utilization. The first three arguments of equation 2 can be simplified to $\triangle C F$. The values for CW1to CW4 are all the same $(C W)$. So simplified we get

$$
\Delta C F_{t=y}-C W_{t=y}+C W_{t=y+z}=\Delta C A T M_{t \in\{y, y+z\}}
$$

The left part of equation 3 consists of several pulse emissions occurring at different times and can therefore be interpreted as an emission profile of the system. Dynamic LCA is used to calculate the climate impact of the emission profiles while addressing the temporality of emissions (Levasseur et al. 2010): First, cynamic characterization Factors (DCF) are obtained (equation 4) by step-wise calculating the cumulative radiative forcing from a factor for radative efficiency $(\alpha)$ and the impulse response function $(\operatorname{IRF}(t))$, which describes the decay of a GHG in the atmosphere (here only CO2 is considered). Then, annual emissions $g_{y}$ are multiplied with their respective DCF and are summed up over the whole life cycle and again over each year, to yield the cumulated time dependent impact on global warming $G W I_{\text {cum }}$ (equation 5). Last, by dividing $G W I_{\text {cum }}$ of a certain time horizon $T H$ by the cumulative radiative forcing of a reference emission at time zero, the total GWP is obtained (equation 6).

$$
\begin{gathered}
D C F_{t}=\int_{t-1}^{t} \alpha * I R F(t) d t \\
G W I_{c u m}\left(T H, g_{y}\right)=\sum_{Y=0}^{T H} \sum_{y=0}^{Y} g_{y} * D C F_{Y-y} \\
G W P_{\text {dyn500 }}\left(g_{y}\right)=D L C A\left(g_{y}, T H=500\right)=\frac{G W I_{c u m}\left(T H=500, g_{y}\right)}{\int_{t=0}^{T H} \alpha * I R F(t) d t}
\end{gathered}
$$

Up to this point, the forest carbon stock change and temporal storage of carbon in the techno sphere were addressed. The climate impact of substitution (or carbon displacement), is calculated by multiplying a DF with the amount of carbon entering HWP system (which is CW).

$$
C_{\text {displaced }}=C W * D F
$$


Because forest management is the main driver for forest dynamics and wood is its main product, the climate impact of carbon stock changes can be allocated to the extracted wood (Head et al. 2019). The same applies for the climate impact of temporal carbon storage and substitution effects. I.e. all occurring climate impacts induced by the wood extraction of one year, can be allocated to this specific wood extraction (equation 8). By calculating the climate impacts of all wood extractions to the same time horizon, comparability is ensured. A relatively long time horizon of 500 years is used here so that very long storage can be considered.

$G W P_{s, y}=D L C A\left(T H=500, g_{y}=\left(\Delta C F_{s, y, t=y}-C W_{s, y, t=y}+C W_{s, y, t=y+z}-C W_{s, y, t=y} * D F_{y}\right) * \frac{44}{12}\right)$

The global warming potential $G W P$ indicates the climate impact for the wood extraction in year $y$ for a scenario $s . \triangle C F$ stands for the carbon stock change in the forest and $C W$ for the carbon contained in the extracted wood. The subscript $t$ gives the time of the emission and $z$ represents the storage period in years. Accordingly, the forest sink (or source) is represented by $\Delta C F_{s, y, t=y}$. The carbon accounting in the HWP (and by that, the storage of carbon) is represented by $-C W_{s, y, t=y}+C W_{s, y, t=y+z}$. The substitution effect is represented by $-C W_{s, y, t=y} * D F_{y}$ (negative sign because of displacement).

The sum of these effects, $\Delta C F_{s, y, t=y}-C W_{s, y, t=y}+C W_{s, y, t=y+z}-C W_{s, y, t=y} *$ $D F_{y}$ therefore represents the emission profile for a wood extraction in year $y$. The DLCA function describes the application of dynamic LCA to a certain emission profile (equation 4 to 6 ). Since these are given in carbon masses, they must be multiplied by the fraction of the molar mass of carbon in the $\mathrm{CO}_{2}$ molecule $\left(\frac{44}{12}\right)$ to obtain the amount in $\mathrm{kg} \mathrm{CO}_{2}$.

Now, the goal is to find a value for $\mathrm{DF}$ at which the respective wood removals of a certain year achieve the same climate impact for both scenarios. Higher DFs than this value would automatically result in the scenario for intensive forestry (IF) achieving a better climate impact than the scenario for extensive forestry $(\mathrm{EF})$. Therefore, for a value DF for which applies:

$$
G W P_{s=I F, y}=G W P_{s=E F, y}
$$

this value is the required displacement factor (RDF). Hence, if equation 8 is set into equation 9, and the term is resolved for DF, the RDF can be obtained (for details, see appendix):

$R D F_{y}=\frac{D L C A\left(\Delta C F_{I F, y, t=y}-\Delta C F_{E F, y, t=y}-C W_{I F, y, t=y}+C W_{E F, y, t=y}+C W_{I F, y, t=y+z}-C W_{E F, y, t=y+z}\right)}{D L C A\left(-C W_{E F, y, t=y}+C W_{I F, y, t=y}\right)}$

For $D F>R D F$, the wood removal of the intensive forestry has a smaller global warming potential than that of extensive. For $D F<R D F$, the wood removal of intensive forestry has a larger global warming potential than that of extensive. Insights, which can be derived by comparing DF and RDF curves are shown in more detail in figure 2 . 


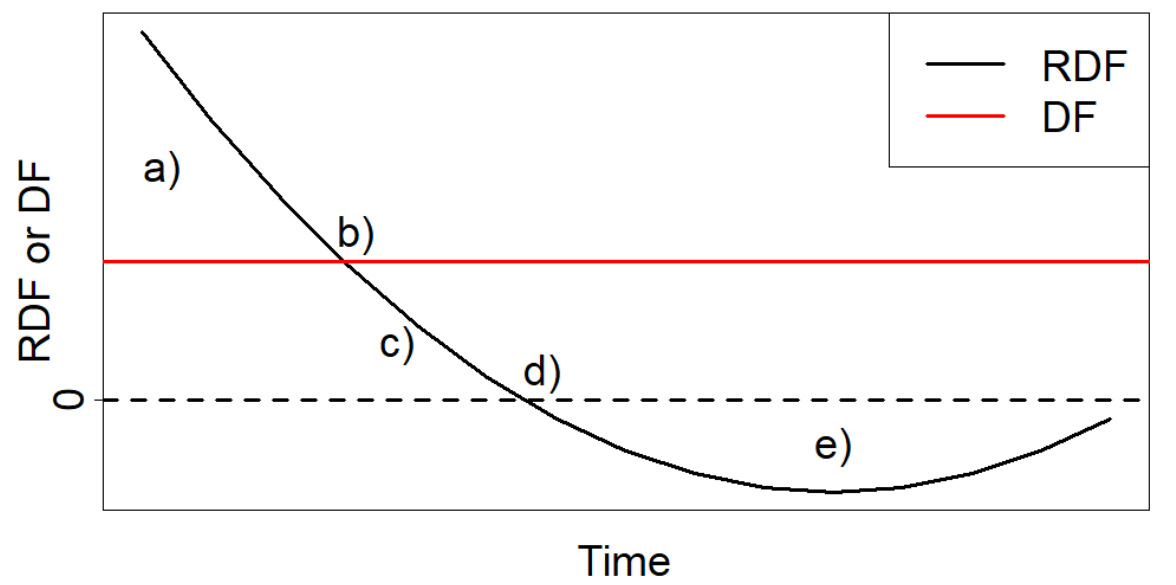

Figure 2: Pseudoplot to illustrate the relationship between DF and RDF cuvres. a) Substitution is needed for annual wood extractions in IF to achieve the same GWP as those in EF $(R D F>0)$. Stronger annual displacement in IF is too low to compensate differences in annual carbon stock changes $(R D F>D F)$.

$\rightarrow$ GWP of annual wood extractions is higher for IF than for EF

b) Substitution is needed for annual wood extractions in IF to achieve the same GWP as those in EF $(R D F>0)$. Stronger annual displacement in IF can compensate differences in annual carbon stock changes $(R D F=D F)$.

$\rightarrow$ GWP of annual wood extractions is the same for IF and EF

c) Substitution is needed for annual wood extractions in IF to achieve lower GWP as those in $\operatorname{EF}(R D F>0)$. Stronger annual displacement in IF is large enough to overcompensate differences in carbon stock changes $(R D F<D F)$.

$\rightarrow$ GWP of annual wood extractions is lower for IF than for EF

d) No substitution is needed for annual wood extractions in IF to achieve the same GWP as those in EF $(R D F=0)$. Stronger annual displacement in IF is large enough to overcompensate differences in carbon stock changes $(R D F<$ $D F)$.

$\rightarrow$ GWP of annual wood extractions is lower for IF than for EF.

e) No substitution is needed for annual wood extractions in IF to achieve lower GWP as those in $\operatorname{EF}(R D F<0)$. Stronger annual displacement in IF is large enough to overcompensate differences in carbon stock changes $(R D F<D F)$.

$\rightarrow$ GWP of annual wood extractions is lower for IF than for EF 


\subsection{Translating climate change mitigation scenarios into Displacement Factors}

With the RDF approach proposed by Seppälä et al. (2019), the forest climate assessment compares two forest management scenarios and is carried out independently of the actual substitution effect of the wood products. In order to make a general statement about which forest management scenario is better suited for climate change mitigation, it is necessary to estimate whether the average DFs of current and future wood utilization can reach calculated RDFs. In order to calculate weighted averages of DFs for different wood usages, the shares of different wood assortments and their use in Germany were compiled from Döring, Glasenapp, and Mantau (2017). These values are based on raw wood use in Germany in 2010. To these use types, substituted materials and their respective DF value were mapped: Wood as construction and non-construction Material substitutes metal, plastic and concrete with a DF of 1.45 Seppälä et al. (2019). Pulp substitutes paper with a DF of 0 as there is no large-scale substitute or alternative way of producing paper. Wood for energetic use substitutes electricity and heat from fossil sources with a DF of 0.8 (Leskinen et al. 2018). These values represent average DFs for 2019 and result from meta studies. Since the underlying system boundaries were not always consistent (Leskinen et al. 2018), they are subject to considerable uncertainties (Tanja Myllyviita et al. 2021). Volume shares of wood usage, was used as weight for calculating averages (Table 1). The resulting current value is similar to the value for an average DF used in Seppälä et al. (2019).

For the estimation of future DFs it is assumed that shares of different uses of wood stay constant. DFs however, are bound to decline due to decarbonization of the energy supply and material prduction sectors (Tanja Myllyviita et al. 2021). Because estimating exact future DFs is very speculative, instead of using fixed values, conservative and optimistic estimates are established and used to define a range of possible DFs. Most studies in the literature estimate reduction potentials until the year 2050 . However, because the government recently formulated climate targets for carbon neutrality in 2045, these reduction potentials are applied for this target year. It is hereby assumed, that these targets can be reached already in 2045 by increasing efforts in fighting climate change. Due to large reduction potentials in the energy and transport sector, it is assumed that GHG emissions caused by wood usage are negligibly small in 2045. Thus, the reduction in a material-specific DF is proportional to the reduction in GHG emissions of the material being substituted (equation 1).

Wood used as construction and non-construction material usually substitutes cement, concrete, metals and plastics (Leskinen et al. 2018). By 2050, it is technically possible to reduce GHG emissions from the steel industry by $99.7 \%$, GHG emissions from the metal industry by $100 \%$, and GHG emissions from the chemical industry by $98.5 \%$ (Benndorf, Bernicke, and Bertram 2014). In the cement industry, decarbonization is more challenging, because of process

emissions in clinker production. How much these emissions can be reduced is currently under research. The German federal environmental agency estimates 
a reduction of $70 \%$ for the concrete sector until 2050- A case study for the concrete production in China found that it should be possible to reduce emissions of concrete production by $50 \%$ until 2050 (Wei and Cen 2019). An up-to-date review on the matter conducted by Habert et al. (2020) also yielded a reduction of $50 \%$ as feasible. Since it is not possible to predict for the future in which quantities the different materials will be substituted, the highest and lowest reduction potential ( $100 \%$ and $50 \%$ respectively) of the mentioned industries are used to represent optimistic and conservative estimates for material substitution in future DFs.

For paper substitution the DF is assumed to stay zero in both conservative and optimistic estimates.

The energy sectors GHG emissions in 2050, could be reduced by 40 to $98 \%$ compared to current values, depending on the right policy (Pehl et al. 2017). Accordingly, these reduction potentials were used to calculate conservative and optimistic estimates for future DFs

Table 1 shows the corresponding DFs (current and future) and wood utilization shares applied for estimating the respective weighted averages. To model the decrease from the current DF to the conservative or optimistic DF, a simple linear interpolation, starting from current values, is used.

Table 1: Shares of wood usages and estimated DFs. Values from the literature where used to calculate the current DF. For future DFs reduction potentials were derived from different studies resulting in a conservative (Con.) and an optimisitic (Opt.) estimate.

\begin{tabular}{|c|c|c|c|c|c|c|}
\hline Consumer & $\begin{array}{l}\text { Volume } \\
{\left[1000 \mathrm{~m}^{3}\right]}\end{array}$ & $\begin{array}{l}\text { Type of } \\
\text { use }\end{array}$ & $\begin{array}{l}\text { Share } \\
{[\%]}\end{array}$ & DF 2019 & $\begin{array}{l}\text { DF } 2045 \\
\text { Con. }\end{array}$ & $\begin{array}{l}\text { DF } 2045 \\
\text { Opt. }\end{array}$ \\
\hline $\begin{array}{l}\text { Sawmill industry } \\
\text { Wood-based panel industry } \\
\text { Veneer and plywood industry }\end{array}$ & $\begin{array}{l}37274 \\
7957 \\
720\end{array}$ & Material & 62.9 & 1.45 & 0.73 & 0 \\
\hline Pulp industry & 6780 & Paper & 9.3 & 0 & 0 & 0 \\
\hline $\begin{array}{l}\text { Biomass combustion plants (big) } \\
\text { Biomass combustion plants (small) } \\
\text { Private households } \\
\text { Pellet and briquette producers }\end{array}$ & $\begin{array}{l}486 \\
664 \\
18612 \\
597\end{array}$ & Energetic & 27.8 & 0.8 & 0.48 & 0.02 \\
\hline Weighted average & & & & 1.13 & 0.59 & $\mathbf{0}$ \\
\hline
\end{tabular}

\subsection{Using RDF and DF to calculate GWP differences}

From the difference between DF and RDF the difference in GWP of the annual wood extractions can be calculated: For $D F=R D F$ annual wood extractions for both scenarios have the same climate impact. Altering DF will only alter $C W_{s, y, t=y} * D F_{y}$. Hence, the difference between RDF and DF multiplied with the difference in annually extracted carbon, yields the annual GWP difference.

$$
\Delta G W P_{y}=\left(R D F_{y}-D F_{y}\right) *\left(-C W_{E F, y, t=y}+C W_{I F, y, t=y}\right)
$$




\subsection{Data}

Two forest growth models for German forests called FaBio and WEHAM are available. With both models a baseline scenario, as well as one of increased and decreased logging was conducted (Sandra Hieke 2018; Oehmichen et al. 2018). The results of the two different models deviate especially in the magnitude of forest carbon stocks (FaBio yields much higher carbon stocks than WEHAM), which led to an intense debate between forest growth modelers. The consequential approach of this work is meant to complement already existing attributive results. For the WEHAM alternative scenarios (not the baseline scenario but increased / decreased logging) climate impacts were assessed by Rüter (2017) in form of GHG balances. Therefore this work is based on the results of the alternative WEHAM scenarios. Accordingly, intensive forest management is represented by the wood preference scenario (WPS) (originally HPS) and extensive forest management is represented by the nature conservation preference scenario (NPS) presented by Oehmichen et al. (2018).

Values for the development of wood stocks and raw wood potentials were taken from Oehmichen et al. (2018) and used to calculate annual carbon stocks and the carbon contained in annual wood extractions. Figure 3 shows the carbon stocks calculated this way and the carbon extracted in raw wood for the two scenarios. To check for plausibility, values from the national greenhouse gas inventory (THGI) from 2017 were added to the graph. Those values lie in between the two scenarios, which makes sense because they represent more extreme forestry regimes than what was practices during the last decade (2010-2020). 

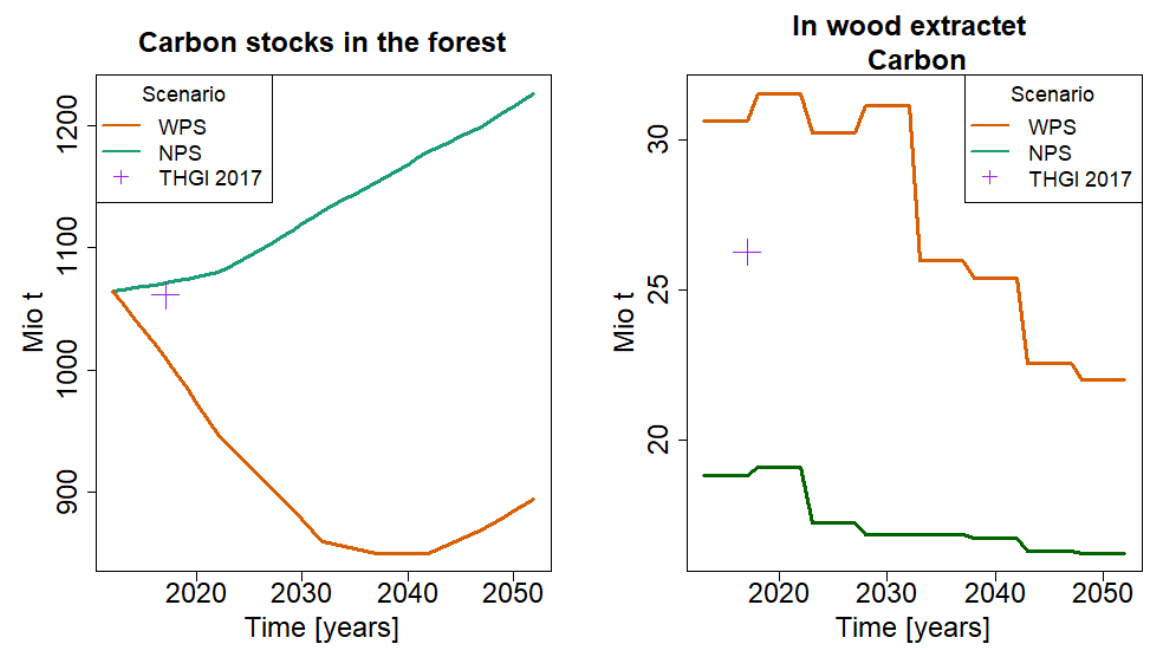

Figure 3: Shows carbon stocks as well as the carbon extracted in raw wood for the alternative WEHAM scenarios. Values were calculated from wood stocks and raw wood potential from Oehmichen et al. (2018) (see Appendix). WPS stands for wood harvest preference scenario. NPS stands for nature conservation preference scenario. To check for plausibility, values from the national greenhouse gas inventory in 2017 were added.

\section{Results}

\subsection{Required Displacement Factors}

The evolution of RDFs over the modeling period is shown in Figure 4. It can be seen that RDFs start at slightly above 1, increase for about 10 years, but start to decrease afterwards. This trend continues, so that RDFs even take on negative values in the last years of the period under study. The initial increasing trend of RDFs is due to the fact that large amounts of wood are harvested in the WPS. Thus, especially in the first years, carbon stocks in the forest decrease sharply compared to the NPS. However, after about ten years, carbon outputs in the NPS also decline while those in the HPS remain relatively high. This changes the RDF's trend, since the NPS shows comparatively low storage and substitution effects. After another ten years, the extractions in the WPS also decrease. At the same time carbon stocks in the WPS fall less rapidly. This leads to a reduction of forest born emissions and within the next ten years the forest becomes a net carbon sink again (Figure 3). As a result, RDF values continue to decline until they reach negative values in the last decade of the period under study. Figure 4 also shows that increasing the average wood product storage time can lower RDFs. However, high storage times are needed for substantial effects. For 2019, the current average DF is about the same as the RDF for an average storage of 1 year. From there, the DFs for different 
climate policy scenarios decrease at different rates. The values of the RDF lay mostly between the two DF curves. Hence, the climate performance of the two forest management scenarios is mainly influenced by how quickly the energy and material production sectors can be decarbonized.

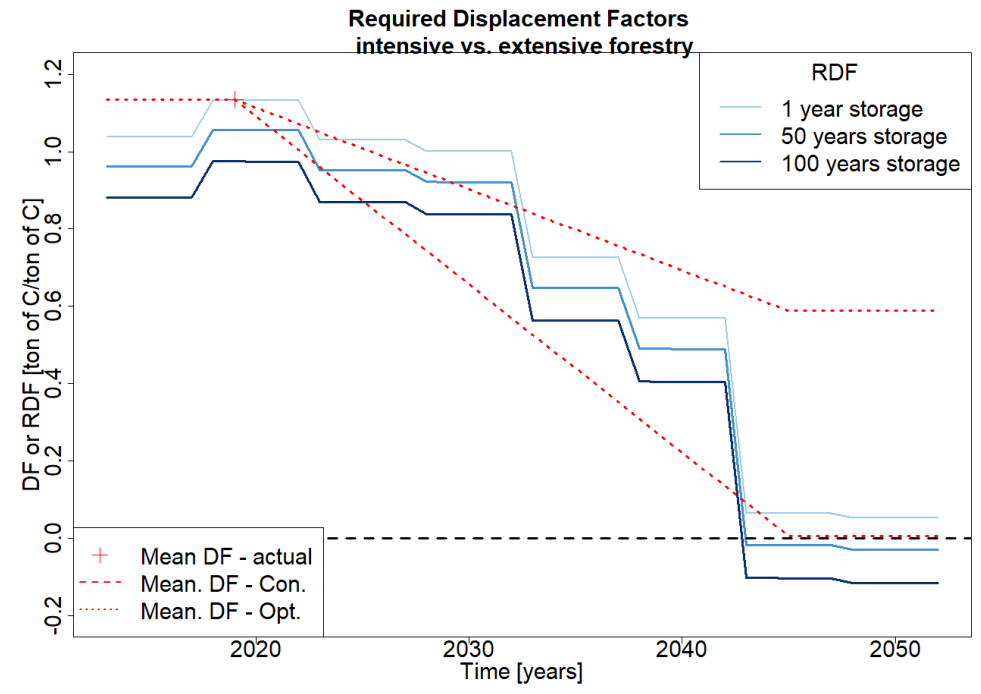

Figure 4: Evolution of RDF so that intensive forest management achieves a positive climate effect compared to extensive forest management. Depending on the average storage period, the curve of RDF shifts. The GWP for the RDF estimation was calculated with a 500 year time horizon. In addition, the current average (weighted mean) DF for wood utilization in Germany is indicated with a red cross and future DFs for different estimates of decarbonization (conservative, optimistic) are shown as dotted lines.

\subsection{GWP differences between forest management scenar- ios under different industry decarbonization pathways}

By comparing DF and RDF, climate-related statements can be made about annual wood removals. In order to obtain a corresponding overall estimate of the respective scenarios, their total GWP must be compared. For this purpose, the annual GWP difference between wood removals of both scenarios can be calculated by multiplying the difference between DFs and RDFs with the difference in extracted carbon between both scenarios (figure 5-a). Since the GWP of wood removals is always calculated for the same time horizon, their differences can simply be added. Figure 5-b shows the cumulative GWP Differences for conservative and optimistic DF estimates with different assumed average storage times. Since the GWP of NPS was subtracted from that of WPS, positive values indicate higher GWP for WPS and negative values indicate higher GWP for NPS. The value at the end of the period under study reflects the total GWP 
difference. The figures show that depending on the DF estimate, one or the other forest management scenario performs better.

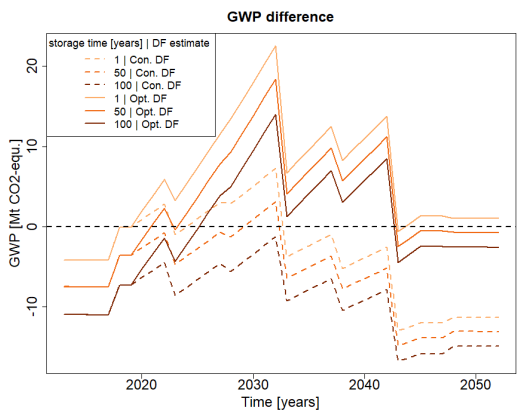

(a)

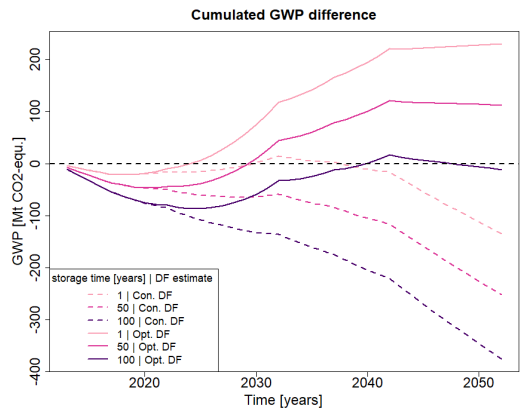

(b)

Figure 5: Shows GWP-differences (WPS-NPS) (a) as well as cumulative GWPdifferences (b) for conservative and optimistic DFs with different average storage times.

\subsection{Sensitivity analysis: Late change in forest manage- ment}

The DF and RDF curves have strikingly similar trends (Figure 4), but one has to keep in mind that both curves characterize different subsystems and that they are derived and calculated from entirely different models. While the evolution of RDFs reflects the dynamics of carbon stocks and wood extractions, DFs are determined by the state of technology and economic factors. The dynamics of both the forest management and the decarbonization scenarios are strong and concurrent. It is instructive to see what happens if there would be a time gap between the shift in forest management and rapid industry decarbonisation. Therefore, as a sensitivity analysis, a temporal offset of 20 years between the curves is simulated by shifting the RDF curve ahead in time. This would be equivalent to a delayed change in forest management practice - assuming that carbon stocks and wood extraction would evolve similarly to the scenarios presented here even after a 20-year continuation of business-as-usual. Shifting the DF curve ahead in time does produce a realistic scenario, because in contrast to a possible change in forest management, the decarbonization of the industry is relatively certain to occur within the next 30 years. The effect of this offset can be seen in Figure 6: If DFs start to decline earlier than RDFs, the GWP difference between WPS and NPS increases. The cumulative GWP difference would be positive at the end of the modeling period for all storage times and DF estimates. Hence, the total GWP of the WPS would be higher than that of the NPS in all cases. 


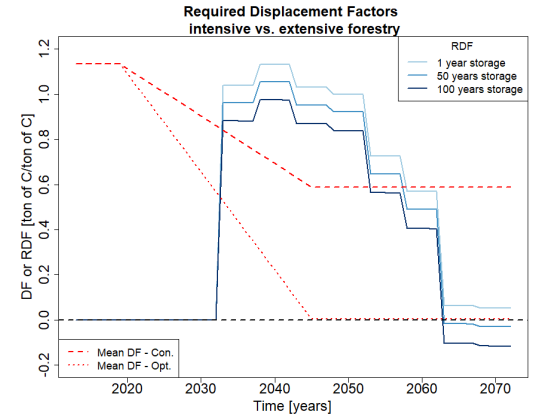

(a)

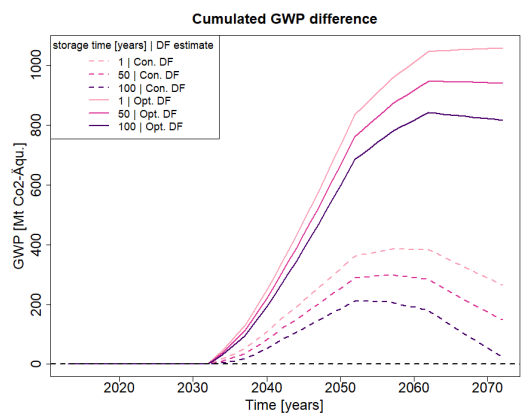

(b)

Figure 6: Shows RDFs (a) and cumulative GWP differences (WPS-NPS) (b) for a late change in forest management 


\section{Discussion}

\subsection{Summary of RDFs for German forests}

The calculated RDFs are influenced by the interaction of carbon stocks and removals of the two scenarios: Within the first ten years of the modeling period, large wood removals in the WPS lead to relatively high RDFs because carbon stocks in the forest are heavily reduced. However, over the next three decades, wood removals in the NPS fall earlier than in the WPS, and then stocks in the WPS begin to rise again, which leads to declining RDFs. Interestingly, carbon stocks in the WPS change at about the same rate as in the NPS by the end of the period under study (Figure 1). At this point, sink and storage effects in the WPS exceed those in the NPS, resulting in small, and even negative RDF depending on the storage time. The development of RDFs over time coincides with the time series for carbon stocks and wood extractions shown in Figure 3. All three indicate that the forest in the WPS experiences a radical transformation from a state of relatively high carbon stocks, towards a state with lower carbon stocks but with similar carbon stock changes and higher wood extractions, compared to a state before intensified logging started. During this transformation however, massive amounts of carbon are leaving the forest in form of timber which can only be stored temporally as wood product. Therefore, higher DFs are needed as compensation to improve the climate performance of the WPS scenario. After the transformation phase, the WPS can achieve a similar climate impact as the NPS even without substitution effects (RDFs are about 0 ). It should be noted, however, that a modeling period of 40 years, which is given by the WEHAM scenarios, is too short to make any statements about whether this trend will continue into the far future.

RDFs can also be used to benchmark climate mitigation strategies for industry against climate change mitigation strategies from forests. Our results show that maximally DFs around 1 are needed so that wood extraction in the WPS achieves the same climate impact as extraction in the NPS. If a product is now substituted with a DF greater than 1, this product substitution renders the intensive forestry scenario as the one with higher emission abatement potential.

\subsection{Matching RDFs with DFs for different decarboniza- tion scenarios}

From figure 4 can be inferred that present substitution effects would be large enough to compensate large wood extractions from the forest $(D F>=R D F)$. With longer storage periods even overcompensation is possible. For the future, the level of compensation is highly dependent on how quickly and intensively energy supply and material production will be decarbonized. As can be seen in Figure 4, the calculated RDFs are mostly below the conservative- but above the optimistic estimate for future DF. This is also reflected in the overall climate impact: The cumulative GWP differences are negative for a conservative 
assumption of future DFs regardless of their average storage time. In contrast, for an optimistic assumption of future DFs, they are all positive. I.e., depending on the DF estimate, the NPS or the WPS performs better in terms of climate impact. This sheds light on the different mitigation strategies which are implicit in those two scenarios: Intensive forestry only performs better if the industry sector cannot be decarbonized properly by 2045 . Therefore it can be seen as a back up plan, in case decarbonization lacks rigor. For extensive forestry to perform better than intensive, ambitious industry carbon neutrality goals have to be largely met. Thus, the role of forest management as a climate change mitigation strategy does not solely depend on forest growth dynamics but also on the climate performance in other sectors. Decision makers should be aware of these cross-sector relationships and elaborate strategies that are robust for any given scenario.

\subsection{The role of timing in the change of forest management}

Another interesting aspect is illuminated by the sensitivity analysis (figure 6): A late change in forest management, simulated by a 20-year shift of the RDF curve, results in positive cumulative GWP differences for both, the conservative and optimistic assumption of future DFs. Such a case is based on the assumption that carbon stocks and wood extractions would be similar to those presented here, even if a change in forest management would be initiated in 2032 only (with forest management between 2012 and 2032 according to current practices). Whether this is the case can be disputed. However, this example illustrates the underlying effect: DFs are very likely to fall within the next few decades. At the same time, intensive forestry requires relatively high DFs during the transformation phase to achieve the same climate impact as extensive forestry. Thus, the later a transition towards more intensive forestry is initiated, the lower DFs will be during the transformation phase of the WPS. Ergo the less likely its climate benefit will be - compared to extensive forestry.

\subsection{Model and data uncertainty and robustness of our central claims}

For all results presented here, substantial uncertainties have to be acknowledged and taken into account. RDFs were calculated from relatively old model results. Since the base scenario of the WEHAM model overestimated wood removals in recent years (Hennenberg et al. 2021), it can be assumed that similar inaccuracies can be found in the alternative WEHAM scenarios. Also, changing forest growth dynamics and disturbance (drought, storm etc.) frequencies due to a changing climate were not incorporated in the alternative WEHAM scenarios. The latter especially affects the NPS scenario because here forests get older and potentially more vulnerable to disturbances such as drought, windthrow or beetle infestation. This would probably lessen the sink effect (Hennenberg 
et al. 2021) in the NPS. Either because damaged wood decomposes or because it needs to be extracted after all. Thus, our finding might be biased towards a falsely enhanced climate performance of the NPS. Alleviating this bias would need a new generation of forest growth scenarios.

In contrast, uncertainties for estimating DFs represent a bias which falsely enhances the climate performance of the WPS as DFs tend to be systematically overestimated (Leturcq 2020). This is because a) apparently the calculations to retrieve DFs are often conducted under the simplifying assumption that biomass is automatically carbon neutral and b) because for substitution to be effective, the demand of the substituted material would also have to be effectively reduced (Leturcq 2020). It is doubtful whether there is a 1:1 substitution based on material performance as assumed for the calculations. It is plausible and more likely that rebound effects influence the calculation of DFs to some extent. If DFs are constantly overestimated, it becomes less likely that they can reach RDFs, which in turn speaks for extensive forestry.

Next to this bias, aggregating values for DFs adds strong uncertainties (Leskinen et al. 2018). Additional uncertainties arise when estimating future DFs. Here, a corridor of possible future values had to be defined, since the exact future trajectory of industry emissions is very speculative at this point. Also, the interpolation between current and future DFs represents a strong simplification.

\subsection{Comparison to the literature}

The RDF results presented here are not as decisive as those in Seppälä et al. (2019). For Finnish forests, the resulting RDFs are even larger than the average current DF. Moreover, the trend in RDFs differs from the results presented here. While RDFs for Germany start to decrease after a few decades, RDFs calculated in Seppälä et al. (2019) continue to increase during this period. This could be due to the different dynamics of forest growth in the respective countries or at least, the underlying models.

Due to the short modeling period of 40 years, the results obtained here are only part of a bigger picture of future forest developement. For example in L. Gustavsson et al. (2021) initial high emissions of intensive forestry were compensated after about 40 years, so that in the long run, it outperformed the extensive forestry scenario. Such cases could of course not be captured with the relatively short modeling period of this study.

\subsection{Synthesis of attributional and consequential results on carbon cycle dynamics}

Combining the attributional and consequential approaches to quantifying the systemic carbon cycle and climate impacts of forest management and wood products use can help clarify the question under study (Table 2). Our work complements the existing attributive scenario results for the alternative WEHAM scenarios in form of GHG balances (Rüter 2017). Within these balances, 
the NPS consistently shows negative values between about -20 and $-30 \mathrm{Mt} \mathrm{CO}_{2}$ per year, while those of the WPS are positive until 2035. From then on they also show negative values up to about $-30 \mathrm{Mt} \mathrm{CO}_{2}$ per year in 2050. Still, the GHG balances are lower for the NPS at all times. The policy relevance of these results is that they can assess, document and report (e.g. in the form of the Kyoto protocol) the sector's climate performance. Usually, climate goals are also sector specific, which allows to compare attributive modelling results to goal setting. With the forest being a GHG source, the WPS cannot meet the LULUCF goal set for 2030. Taking projections of the other categories in that sector (Emele, Harthan, R.,O., and Moosmann 2019) and additional potential mitigation measures such as wetland conservation and humus buildup (Hennenberg et al. 2021) into account, even the sink effect in the NPS is apparently not enough to reach these goals. For that, an incredibly strong sink effect would be necessary. Whether such a strong sink effect is realistic is still a matter of debate among forest growth modellers (J. Bauhus et al. 2021) and calls the feasibility of the proposed goal into question.

In contrast, consequential approaches are not relevant for reporting in climate impact assessments because of their strong dependencies on other sectors or actors. For example, the avoided GHG emissions due to the use of wood products instead of cement, steel, or plastics are a central part of the consequential approach but not part of any attributional sector-based GHG accounting or scenario, which only captures the actual emissions. Due to the inclusion of changes from a baseline the consequential assessments can be very helpful for decision makers by providing understanding of cross-sector interactions and by testing different mitigation strategies against one another. In our case, two different mitigation strategies were studied. One which is in line with other sector's GHG mitigation goals (extensive forestry), and one which serves as back-up plan to help decarbonize these sectors via material substitution (intensive forestry). Which of the two is ultimately the better option to fight climate change cannot be concluded yet due to severe uncertainties and biases - one in favor of extensive forestry (Systematically overestimating DF due to ignorance of rebound effects) and one in favor of intensive forestry (lack of climate change considerations in forest growth modeling).

One robust conclusion, however, is that the question which scenario outperforms the other in terms of climate impact, is directly linked to successful decarbonization in other sectors. If deep decarbonization is successful, extensive forestry outperforms intensive - and vice versa. Another certain conclusion is that the climate performance of extensive forestry compared to intensive forestry improves with every year for which a change in forest management is not initiated. Decisions on appropriate forest management strategies should therefore not only be made on the basis of forest growth models, but also in light of the political will to decarbonize the energy supply and material production. 
Table 2: Summarizes the main findings of the attributional and consequential scenario comparison. Results for the attributional approach are taken from Rüter (2017) . The properties superior, beneficial and adverse relate to the respective scenarios performance in climate change mitigation. Policy refers to the support each approach offers in policy making.

\begin{tabular}{|c|c|c|c|c|}
\hline & Policy & & WPS & 'NPS \\
\hline \multirow{4}{*}{ 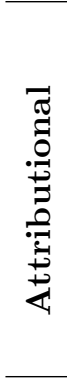 } & \multirow{4}{*}{$\begin{array}{l}\text { Assessing, } \\
\text { Document- } \\
\text { ing, } \\
\text { Reporting } \\
\text { (Sector } \\
\text { specific) }\end{array}$} & $\begin{array}{l}\text { GHG Bal- } \\
\text { ance }(2030)\end{array}$ & $\sim+10$ Mt CO2-eq. & $\sim-30$ Mt CO2-eq. \\
\hline & & $\begin{array}{l}\text { GHG Bal- } \\
\text { ance }(2040)\end{array}$ & $\sim-10$ Mt CO2-eq. & $\sim-30 \mathrm{Mt} \mathrm{CO} 2$-eq. \\
\hline & & $\begin{array}{l}\text { GHG Bal- } \\
\text { ance }(2045)\end{array}$ & $\sim-20$ Mt CO2-eq. & $\sim-30$ Mt CO2-eq. \\
\hline & & $\begin{array}{l}\text { Goals for } \\
\text { LULUCF } \\
\text { reachable }\end{array}$ & very unlikely / impossible & unlikely \\
\hline \multirow{4}{*}{ 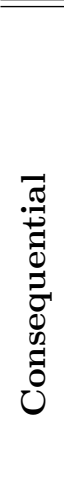 } & \multirow{4}{*}{$\begin{array}{l}\text { Strategy } \\
\text { Testing, } \\
\text { Decision } \\
\text { Making } \\
\text { (cross- } \\
\text { sector) }\end{array}$} & $\begin{array}{l}\text { Climate Im- } \\
\text { pact } \\
\text { Mitigation } \\
\text { Strategy }\end{array}$ & $\begin{array}{l}\text { Superior if decarbonization } \\
\text { takes long and is less intense } \\
\rightarrow \text { Back up if goals in other } \\
\text { sectors are not met }\end{array}$ & $\begin{array}{l}\text { Superior if decarbonization is } \\
\text { rapid and intense } \\
\rightarrow \text { In line with goals for other } \\
\text { sectors }\end{array}$ \\
\hline & & $\begin{array}{l}\text { Increasing } \\
\text { disturbances }\end{array}$ & Beneficial & Adverse \\
\hline & & \multicolumn{2}{|c|}{$\begin{array}{l}\text { Overestimation Adverse } \\
\text { of DFs }\end{array}$} & Beneficial \\
\hline & & $\begin{array}{l}\text { Timing } \\
\text { of change } \\
\text { in Forest } \\
\text { Management }\end{array}$ & $\begin{array}{l}\text { Superior if change in forest } \\
\text { management is initiated im- } \\
\text { mediately }\end{array}$ & $\begin{array}{l}\text { Superior if change in forest } \\
\text { management is initiated rel- } \\
\text { atively late (the later the } \\
\text { more beneficial). }\end{array}$ \\
\hline
\end{tabular}

\section{Conclusion}

With the help of RDF, the consequential aspect of the climate impact of different forest management scenarios could be assessed. Temporal storage of carbon could be incorporated with dynamic LCA, so that the uncertainty arising form HWP stock estimation was eliminated. The scenario comparison showed that during a transformation from high to low carbon stocks in the intensive forest management scenario, relatively high DFs are needed to compensate for the carbon losses. After the transformation, no more substitution would be needed as carbon stock changes are similar in both scenarios. The maximal RDF of about 1 can be seen as benchmark, meaning that the displacement of a material with DFs above that value definitely support intensive forestry.

Which of the two scenarios performs better in terms of overall climate impact depends on the speed and intensity of industry decarbonization. For an optimistic estimate (mostly complete decarbonizaion of energy and material production until 2045), the extensive scenario achieves a lower total GWP. For a conserva- 
tive estimate (limited decarbonization until 2045, especially in cement/concrete production), on the other hand, the intensive scenario. These results are subject to severe biases. The numbers used for DFs are overestimates due to the negligence of rebound effects which may falsely enhance the climate performance of intensive forestry. Meanwhile, not regarding the influence of climate change on the forest growth modelling may falsely enhance the climate performance of extensive forestry. Despite these uncertainties, crucial insights for the ForestHWP system can be derived.

The dependency between climate impacts of both scenarios and decarbonization in the industry shifts the focus from forest sector related decision makers only, towards incorporating industry-related political and private actors as well. The key parameter seems to be the political will to decarbonize industrial production. With reliable prospects or trajectories for that matter, the appropriate mitigation strategy for the forest sector could be chosen. Climate goals for the LULUCF sector could then be set in accordance to the chosen mitigation strategy.

Additionally, choosing the right strategy is time-dependent. The later a change in forest management is to be initiated, the smaller actual DFs will be. Hence, with every year, where change is not initiated, extensive forestry becomes more likely to effectively combat climate change compared to intensive forestry. Our results indicate, that if change was initiated after the next decade only, exten-

sive forestry would be likely to climate-wise outperform intensive forestry in Germany.

\section{Declarations}

\section{Ethics approval and consent to participate}

Not applicable

\section{Consent for publication}

Not applicable

\section{Availability of data and material}

All data generated or analysed during this study are included in this published article and its supplementary information files.

\section{Competing interests}

The authors declare that they have no competing interests. 


\section{Funding}

The research that led to this publication was in part funded by the German Agency for Renewable Resources (FNR), funding key 2218WK07C3.

\section{Authors' contributions}

CB compiled the relevant data and elaborated the methodology together with SP. The calculation and presentation of the result was conducted by CB. The main body of the manuscript was written by $\mathrm{CB}$ with SP adding substantial

contributions to the text and argument. Both authors read and approved the final manuscript.

\section{Acknowledgements}

Not applicable. 


\section{References}

Bauhus, J. et al. (2021). Geplante Änderung des Klimaschutzgesetzes riskiert Reduktion der potenziellen Klimaschutzbeiträge von Wald und Holz. Stellungnahme. Ed. by Wissenschaftlicher Beirat für Waldpolitik. Berlin. URL: https : / / www . bmel . de / SharedDocs / Downloads / DE / _Ministerium / Beiraete/waldpolitik/klimaschutzgesetz.pdf?_-blob=publicationFile\& $\mathrm{v}=5$.

Bauhus, Jürgen et al. (2018). Waldvision Deutschland - Orientierung oder Irrweg für eine nachhaltige multifunktionale Forstwirtschaft? Stellungnahme des Wissenschaftlichen Beirates Waldpolitik zur Studie Waldvision Deutschland des Öko-Instituts e. V. im Auftrag von Greenpeace e. V. Ed. by Wissenschaftlicher Beirat für Waldpolitik. URL: https://www. bmel.de/SharedDocs/ Downloads/DE/_Ministerium/Beiraete/waldpolitik/StellungnahmeWBWWaldvisionDeutschland.pdf?_-_blob=publicationFile\&v=3.

Baul, Tarit Kumar et al. (2020). "Radiative forcing of forest biomass production and use under different thinning regimes and initial age structures of a Norway spruce forest landscape". In: Canadian Journal of Forest Research

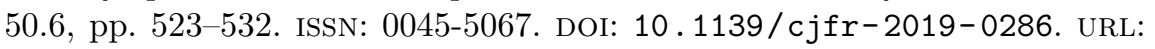
https://doi.org/10.1139/cjfr-2019-0286.

Benndorf, R., M. Bernicke, and A. Bertram (2014). Climate Change 07/2014 Treibhausgasneutrales Deutschland im Jahr 2050. Ed. by Umweltbundesamt. URL: https://www. umweltbundesamt.de/sites/default/files/medien/ 378/publikationen/07_2014_climate_change_dt.pdf.

BMEL (2021). Zweiter Nationaler Waldgipfel 2021. URL: https://www.bmel. $\mathrm{de} / \mathrm{DE} /$ themen/wald/wald-in-deutschland/waldgipfel-2021.html.

Böttcher, Hannes et al. (2018). Reaktion auf die Stellungnahme des Wissenschaftlichen Beirates für Waldpolitik (WBW) zur Studie Waldvision Deutschland. Ed. by Oeko-Institut e.V. URL: https://www .oeko.de/fileadmin/oekodoc/ Waldvision-Reaktion-Stellungnahme-WBW.pdf.

Brander, Matthew, Roger L. Burritt, and Katherine L. Christ (2019). "Coupling attributional and consequential life cycle assessment: A matter of social responsibility". In: Journal of Cleaner Production 215, pp. 514-521. ISSN: 09596526. DOI: $10.1016 / \mathrm{j} \cdot \mathrm{jclepro} .2019 .01 .066$.

Döring, Przemko, Sebastian Glasenapp, and Udo Mantau (2017). "Regionale Derbholzverwendung und Vergleich zum WEHAM-Derbholzpotenzial: Abschlussbericht zum Teilvorhaben des Verbundforschungsprojekts WEHAMSzenarien (AP 3.2)". In: URL: https://www . weham-szenarien.de/fileadmin/ weham / Ergebnisse / Regionale _ Derbholzverwendung _ und _ Vergleich _ zum_WEHAM-Derbholzpotenzial.pdf.

Ekvall, Tomas (2019). "Attributional and Consequential Life Cycle Assessment". In: Sustainability Assessment at the 21st century. URL: https : / / www . intechopen. com/chapters/69212.

Emele, Lukas, Harthan, R.,O., and L. Moosmann (2019). Projektionsbericht 2019 für Deutschland - Zusammenfassung in der Struktur des Klimaschutzplans. Ed. by Umweltbundesamt. URL: https : //www . umweltbundesamt . 
de / sites / default / files / medien / 1410 / publikationen / 2019 - 09 06_climate-change_33-2019_pb19-ksp2050_teilbericht-psz-ix.pdf.

Gustavsson, L. et al. (2021). "Climate effects of forestry and substitution of concrete buildings and fossil energy". In: Renewable and Sustainable Energy Reviews 136.3, p. 110435. ISSN: 13640321. DOI: 10 .1016/j .rser. 2020. 110435.

Gustavsson, Leif et al. (2017). "Climate change effects of forestry and substitution of carbon-intensive materials and fossil fuels". In: Renewable and Sustainable Energy Reviews 67.1, pp. 612-624. ISSN: 13640321. DOI: 10.1016/ j.rser.2016.09.056.

Habert, G. et al. (2020). "Environmental impacts and decarbonization strategies in the cement and concrete industries". In: Nature Reviews Earth \& Environment 1.11, pp. 559-573. DOI: 10.1038/s43017-020-0093-3.

Head, Marieke et al. (2019). "Forestry carbon budget models to improve biogenic carbon accounting in life cycle assessment". In: Journal of Cleaner Production 213.5, pp. 289-299. ISSN: 09596526. DOI: 10.1016/j.jclepro. 2018.12.122.

Hennenberg, Klaus et al. (2021). Interpretation des Klimaschutzgesetzes für die Waldbewirtschaftung verlangt adäquate Datenbasis - Reaktion auf die Stellungnahme des Wissenschaftlichen Beirats für Waldpolitik beim BMEL (vom 22.06.2021). Ed. by Oeko-Institut e.V. URL: https://www. oeko.de/ fileadmin/oekodoc/03-WP-Klimaschutzgesetz-Waldbewirtschaftung. pdf.

Hiraishi, T. et al. (2014). Revised Supplementary Methods and Good Practice Guidance Arising from the Kyoto Protocol. Ed. by Intergovernmental panel on climate change.

Höglmeier, Karin et al. (2015). "LCA-based optimization of wood utilization under special consideration of a cascading use of wood". In: Journal of environmental management 152 , pp. 158-170. DOI: 10.1016/j.jenvman. 2015. 01.018.

Kalliokoski, Tuomo et al. (2020). "Mitigation Impact of Different Harvest Scenarios of Finnish Forests That Account for Albedo, Aerosols, and Trade-Offs of Carbon Sequestration and Avoided Emissions". In: Frontiers in Forests and Global Change 3, p. 1227. DOI: 10.3389/ffgc.2020.562044.

Leskinen, Pekka et al. (2018). Substitution effects of wood-based products in climate change mitigation. Ed. by European Forest Institute. DOI: 10.36333/ fs07. URL: https://doi.org/10.36333/fs07.

Leturcq, Philippe (2020). "GHG displacement factors of harvested wood products: The myth of substitution". In: Scientific reports 10.1, p. 20752. DOI: 10.1038/s41598-020-77527-8.

Levasseur, Annie et al. (2010). "Considering time in LCA: Dynamic LCA and its application to global warming impact assessments". In: Environmental science $E$ technology 44.8, pp. 3169-3174. DOI: 10.1021/es9030003.

Oehmichen, Katja et al. (2018). Die alternativen WEHAM-Szenarien: Holzpräferenz, Naturschutzpräferenz und Trendfortschreibung: Szenarienentwicklung, Ergebnisse und Analyse. Vol. 59. Thünen Report. Braunschweig, Germany: Jo- 
hann Heinrich von Thünen-Institut. ISBN: 9783865761842. DOI: 10 .3220/ REP1527686002000. URL: http://hdl.handle.net/10419/180212.

Pehl, Michaja et al. (2017). "Understanding future emissions from low-carbon power systems by integration of life-cycle assessment and integrated energy modelling". In: Nature Energy 2.12, pp. 939-945. ISSN: 2058-7546. DOI: 10. 1038/s41560-017-0032-9.

Pingoud, K. et al. (2006). Harvested Wood Products. Ed. by Intergovernmental panel on climate change. URL: https : //www .ipcc-nggip.iges .or.jp/ public/2006gl/pdf/4_Volume4/V4_12_Ch12_HWP.pdf.

Pukkala, Timo (2014). "Does biofuel harvesting and continuous cover management increase carbon sequestration?" In: Forest Policy and Economics 43.4, pp. 41-50. ISSN: 13899341. DOI: 10.1016/j.forpol.2014.03.004.

Rüter, Sebastian (2017). "Treibhausgasbilanzen der WEHAM-Szenarien". In: AFZ-DerWald 13, pp. 30-31.

Sandra Hieke (2018). Wenn Wälder wieder wachsen. Ed. by Greenpeace. URL: https : / / www . greenpeace . de / sites / www . greenpeace . de / files / publications/s02061_greenpeace_studie_waldvision.pdf.

Sathre, Roger and Jennifer O'Connor (2010). "Meta-analysis of greenhouse gas displacement factors of wood product substitution". In: Environmental Science $\&$ Policy 13.2, pp. 104-114. ISSN: 14629011. DOI: 10.1016/j. envsci. 2009.12 .005$.

Seppälä, Jyri et al. (2019). "Effect of increased wood harvesting and utilization on required greenhouse gas displacement factors of wood-based products and fuels". In: Journal of environmental management 247, pp. 580-587. DOI: $10.1016 / \mathrm{j}$. jenvman.2019.06.031.

Soimakallio, Sampo et al. (2021). "On the trade-offs and synergies between forest carbon sequestration and substitution". In: Mitigation and Adaptation Strategies for Global Change 26.1, p. 182. ISSN: 1381-2386. DOI: 10.1007/ s11027-021-09942-9.

Tanja Myllyviita et al. (2021). "Wood substitution potential in greenhouse gas emission reduction-review on current state and application of displacement factors". In: Forest Ecosystems 8.1, pp. 1-18. URL: https://doi .org/10. 1186/s40663-021-00326-8.

Wei, Junxiao and Kuang Cen (2019). "A preliminary calculation of cement carbon dioxide in China from 1949 to 2050". In: Mitigation and Adaptation Strategies for Global Change 24.8, pp. 1343-1362. ISSN: 1381-2386. DOI: 10. 1007/s11027-019-09848-7.

$\mathrm{Xu}$, Zhen et al. (2018). "Climate change mitigation strategies in the forest sector: Biophysical impacts and economic implications in British Columbia, Canada". In: Mitigation and adaptation strategies for global change 23.2, pp. 257-290. DOI: 10.1007/s11027-016-9735-7.

Yang, Hongqiang and Xiaobiao Zhang (2016). "A Rethinking of the Production Approach in IPCC: Its Objectiveness in China". In: Sustainability 8.3, p. 216. ISSN: 2071-1050. DOI: $10.3390 /$ su8030216.

Zhang, Xiaobiao et al. (2020). "Improving Carbon Stock Estimates for InUse Harvested Wood Products by Linking Production and Consumption-A 
Global Case Study". In: Environmental science 83 technology 54.5, pp. 25652574. DOI: 10.1021 /acs .est.9b05721. 


\section{Supplementary Files}

This is a list of supplementary files associated with this preprint. Click to download.

- SupplementaryMaterial.pdf 